УДК 681.51.622.7

DOI https://doi.org/10.32838/2663-5941/2019.4-1/17

\title{
Kyniн A.I.
}

Криворізький національний університет

Сенько А.O.

Криворізький національний університет

\section{Мисько Б.С.}

Криворізький національний університет

\section{ОПТИМІЗАЦІЇ НА ОСНОВІ ГЕНЕТИЧНИХ ПІДХОДІВ ДЛЯ ПРОЦЕСУ ЗБАГАЧЕННЯ ЗАЛІЗНОЇ РУДИ}

3 оглядуна те, що завдання оптимізачії процесу збагачення залізноїруди є задачею глобальної оптимізаиії в умовах нестаціонарності та нелінійності, з метою ї̈ вирішення було застосовано принципи генетичних алгоритмів. У процесі дослідження проведено оптимізацію багатовимірної функції мети, яку сформовано у прочесі нейромережевої ідентифікачії технологічного прочесу збагачення магнетитових кваричтів. Вважається, що всі можливі обмеження у вигляді рівностей або нерівностей вже враховані в иільовій функиї̈ у вигляді згортки критеріїв, за допомогою методу штрафних функиій або іншим чином. Для спрощення будемо вважати, що функція мети включатиме лише продуктивність, клас крупності, вміст заліза. Хоча аналогічна методика може бути застосована і для більшої кількості чинників. Причому незалежно від вибору головного критерію відомо, що завдання мінімізачї та максимізаиії еквівалентні. Встановлено необхідну точність оптимізаиії для функиії: два знаки після коми. У кожній генерації оцінюється кожна хромосома на предмет ї̈ придатності з використанням функиії $f$ на декодованому наборі змінних. Відбирається нова популяція з огляду на розраховану придатність. За допомогою операторів схрещування і мутації хромосоми комбінуються в нову популяцію. Після відбору, схрещування й мутащії нова популяція готова для подальшого оцінювання. Отримані оцінки використовуються для побудови нової рулетки із секторами, пропориійним поточним значенням функиії придатності. Інша частина еволючії являє собою циклічне повторення процесу. Після деякого числа генерацій, коли не спостерігається поліпшення популящії, краща хромосома представляє оптимальне рімення. Можлива також примусова зупинка алгоритму після фіксованого числа ітерацій. Застосовано генетичні оператори селекиї̈ та мутаиії. Це дало змогу просунутися вперед на шляху пошуку максимального значення розглянутої функції.

Ключові слова: генетичні алгоритми, оптимізація, збагачення залізної руди, схрещення, мутація.

Постановка проблеми. Завдання оптимізації цільової функції на основі нейронних мереж в умовах збагачувальної технології, як і більшість реальних задач багатофакторної оптимізації, $\epsilon$ багатоекстремальним та погано зумовленим. Тому всі класичні методи оптимізації, що грунтуються на використанні градієнта цільової функції, не можуть гарантувати знаходження найкращого рішення [2].

Аналіз останніх досліджень i публікацій. Численні дослідження довели, що ГА $є$ одним із кращих методів, що забезпечують вирішення багатомірних та багатоекстремальних завдань глобальної оптимізації в умовах нестаціонарності та нелінійності [3]. Дослідження [4; 5] підтвердили доцільність застосування підходу на основі процедури з ГА гаплоїдної версії задля оптиміза- ції керування в умовах процесів збагачувальної технології.

Розглянемо принципи застосування ГА для оптимізації багатовимірної функції мети, яку сформовано у процесі нейромережевої ідентифікації ТП збагачення магнетитових кварцитів. Використаємо підхід застосування генетичних алгоритмів, що запропонований авторами [1].

Постановка завдання. Таке завдання нелінійного програмування із застосуванням ГА узагальнено формулюється як:

$$
f\left(\chi^{*}\right)=\min f(\underset{\chi \in X}{\chi}),
$$

де $\chi \in \Re$ - вектор координат точки пошуку; $\chi^{*}$ - оптимальне рішення; X - область пошуку.

Крім того, припустимо, що цільова функція $f$ може приймати лише позитивні значення; 
у протилежному випадку варто додати певне постійне значення, наприклад,

де $C$ - константа.

$$
\max f(\chi)=\max \{f(\chi)+C\}
$$

Можливе вирішення задачі (3.1) представляється в ГА у вигляді особини $\{\chi, f(\chi)\}$. Вона включає вектор $\chi\left(\chi_{1}, \chi_{2}, \ldots, \chi_{l}\right)$, що закодований у 1 лінійних хромосомах (одна на кожну координату), а також відповідне значення цільової функції $f(\chi)$.

Отже, завдання полягає в максимізації функціï k змінних $f\left(\chi_{1}, \ldots, \chi_{k}\right)$; при цьому кожна змінна $\chi_{i}(i=\overline{1, k})$ приймає значення в межах області $D_{i}=\left[a_{i}, b_{i}\right]$ та $f\left(\chi_{1}, \ldots, \chi_{k}\right)>0$ для кожного $\chi_{i} \in D_{i}$.

Встановимо необхідну точність оптимізації для функції $f(\chi): 2$ знаки після коми. Тоді кожна область $D_{i}$ має бути розділена на $\left(b_{i}-a_{i}\right) \times 10^{2}$ однакових відрізків.

Позначимо через ті найменше число, що задовольняє нерівності

$$
\left(b_{i}-a_{i}\right) \times 10^{6} \leq 2^{m}-1 .
$$

Тоді кожна змінна $\chi і$ кодується як бінарний рядок довжиною ті, що відповідає заданій точності.

Виклад основного матеріалу дослідження. Кожна хромосома (потенційне рішення) представляється бінарним рядком довжиною $m=\sum_{i}^{k} m_{i}$. У цьому рядку перші $m_{1}$ бітів позначають $\chi_{1} 3$ діапазону $\left[a_{1}, b_{1}\right]$, другі $m_{2}-3$ діапазону $\left[a_{2}, b_{2}\right]$ i т.д. Зрештою, хромосома має такий вигляд:

$$
\underbrace{01010}_{m_{1}} \underbrace{1110}_{m_{2}} 0011 \underbrace{1100}_{m_{k}}
$$

Задаємо, крім того, розмір популяції $M$ (число хромосом).

Далі робота ГА здійснюється відповідно до алгоритму (рис. 1).

- у кожній генерації оцінюється кожна хромосома на предмет їі придатності з використанням функції $f$ на декодованому наборі змінних;

- відбирається нова популяція 3 огляду на розраховану придатність;

- за допомогою операторів схрещування i мутації хромосоми комбінуються в нову популяцію.

Після деякого числа генерацій, коли не спостерігається поліпшення популяції, краща хромосома представляє оптимальне (можливо, глобальне) рішення. Можлива також примусова зупинка алгоритму після фіксованого числа ітерацій.

Для процесу селекції служить рулетка (генератор випадкових чисел $[6,7])$ із розмірами секторів, пропорційних придатності кожного рядка. Розробка такої рулетки складається 3 таких кроків:

- обчислюється придатність $\propto\left(a_{j}\right)$ для кожної хромосоми $a_{j}, j=\overline{1, M}$;

- знаходиться загальна функція придатності всієї популяції $F=\sum_{j}^{M} \mu\left(a_{j}\right)$;

- визначається ймовірність вибору $p_{j}$ для хромосом $a_{j} p_{j}=m\left(a_{j}\right) / F$;

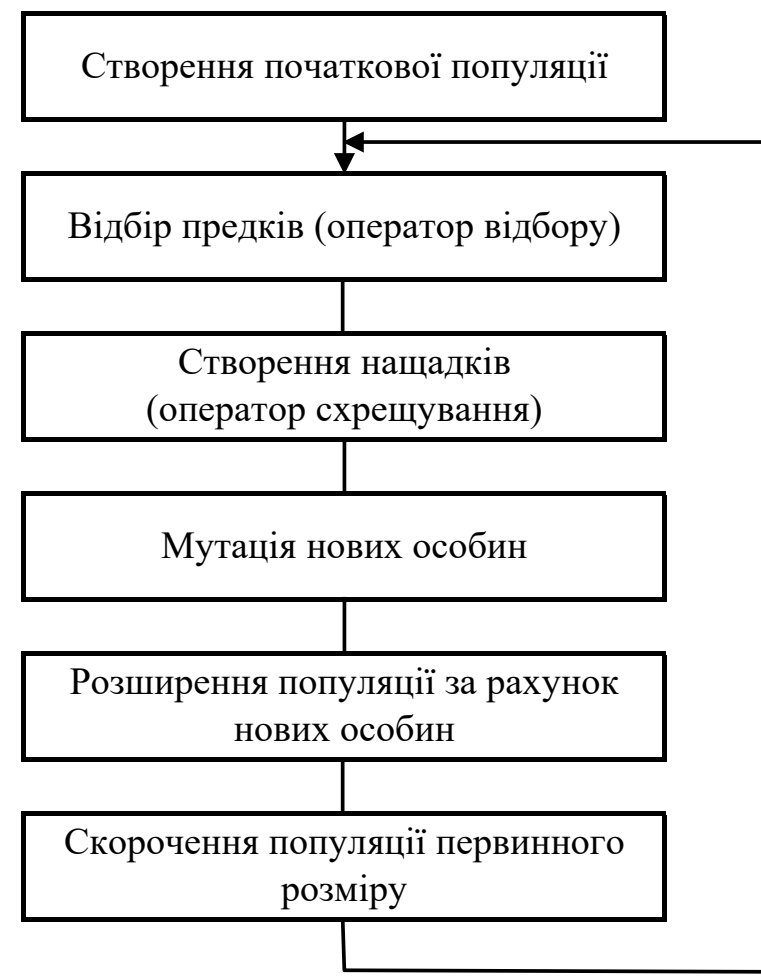

Рис. 1. Блок-схема роботи генетичного алгоритму (ГА) 
- обчислюється кумулятивна імовірність $q_{j}$ кожної хромосоми $q_{j}=\sum_{j=1} p_{j}$.

Процес селекції заснований на обертанні колеса $M$ раз, і щоразу відбирається одна хромосома в нову популяцію в такий спосіб:

- генерується випадкове число $r$ д діапазону $[0,1]$

- якщо $r<q_{1}$, то вибирається перша хромосома $a_{1}$; у протилежному випадку відбирається $j$-та хромосома $a_{j}(2 \leq j \leq M)$ таким чином, щоб $q_{j-1}<r \leq q_{j}$.

Очевидно, що деякі хромосоми будуть обрані більше ніж один раз. Кращі хромосоми дають більше копій, середні залишаються незмінними, погані вмирають. Нові рішення на цьому етапі не створюються.

Задається ймовірність схрещування $p_{c}$. Очікуване число хромосом, які піддаються схрещуванню, становить $p_{c}$ х $M$.

Для кожної хромосоми 3 нової популяції:

- генерується випадкове число $r$ діапазону $[0,1]$

- якщо $r<p_{c}$ то ця хромосома вибирається для схрещування.

У такий спосіб відбираються особини для схрещування. Вибір точки схрещування теж випадко- вий. Генерується випадкове число $s$ з діапазону $[1 \ldots(m-1)](m$ - довжина хромосоми). Це число $s$ визначає точку схрещування.

У підсумку дві хромосоми $\left(b_{1} b_{2} \ldots b_{s} b_{s+1} \ldots b_{m}\right)$ i $\left(c_{1} c_{2} \ldots c_{s} c_{s+1} \ldots c_{m}\right)$ заміняються парою нащадків $\left(b_{1} b_{2} \ldots b_{s} c_{s+1} \ldots c_{m}\right)$ i $\left(c_{1} c_{2} \ldots c_{s} b_{s+1} \ldots b_{m}\right)$.

Мутація. Задається ймовірність мутації $p_{m}$. Очікуване число змінених бітів становитиме $p_{m}$ х $m \times M$. Кожен біт у всіх хромосомах у всій популяції має рівний шанс піддатися мутації, тобто змінитися 30 на 1 або навпаки. Це здійснюється в такий спосіб:

- генерується випадкове число $r$ діапазону $[0,1]$;

- якщо $r<p_{m}$, то біт змінюється.

Після відбору, схрещування й мутації нова популяція готова для подальшого оцінювання. Отримані оцінки використовуються для побудови нової рулетки з секторами, пропорційним поточним значенням функції придатності. Інша частина еволюції являє собою циклічне повторення процесу.

Скористаємося наведеними поясненнями для вирішення завдання оптимізації цільової функції, яку отримано в результаті нейромережевого

\section{Початкова популяція для оптимізації}

Таблиця 1

\begin{tabular}{|c|c|c|c|}
\hline № & Рядки із закодованими хромосомами & № & Рядки із закодованими хромосомами \\
\hline 1 & 0000001111111010011011111 & 10 & 1000110000011010000111011 \\
\hline 2 & 0100110111001010100011010 & 11 & 1110110101100001101111000 \\
\hline 3 & 0011001000001010111011101 & 12 & 0111101101000101010000000 \\
\hline 4 & 0101101001111000001110010 & 13 & 1010001000110000001000110 \\
\hline 5 & 1001010011010111111000101 & 14 & 1000001010100111100101001 \\
\hline 6 & 0010010101001010111111011 & 15 & 1101110000100011111011110 \\
\hline 7 & 0000110101111011011111011 & 16 & 0000011111100001101001011 \\
\hline 8 & 0001110100010110101100111 & 17 & 1111001111010001101111101 \\
\hline 9 & 0101100010110000001111100 & 18 & 0000001110100111110101101 \\
\hline 10 & 1000110000011010000111011 & 19 & 0011111111110000110001100 \\
\hline 11 & 1110110101100001101111000 & 20 & 0110011110011000101111110 \\
\hline
\end{tabular}

Початкова популяція для оптимізації

\begin{tabular}{|c|c|c|c|c|c|}
\hline Номер рядка & Функція & Придатність & Номер рядка & Функція & Придатність \\
\hline 1 & $\mathrm{f}(29,25 ; 31,56)$ & 129,64 & 11 & $\mathrm{f}(67,94 ; 31,11)$ & 136,91 \\
\hline 2 & $\mathrm{f}(41,48 ; 31,63)$ & 109,73 & 12 & $\mathrm{f}(49,03 ; 30,8)$ & 128,75 \\
\hline 3 & $\mathrm{f}(36,89 ; 31,88)$ & 121,23 & 13 & $\mathrm{f}(55,48 ; 30,09)$ & 125,69 \\
\hline 4 & $\mathrm{f}(43,59 ; 30,14)$ & 139,56 & 14 & $\mathrm{f}(50,25 ; 32,29)$ & 134,74 \\
\hline 5 & $\mathrm{f}(53,27 ; 32,49)$ & 136,75 & 15 & $\mathrm{f}(65,09 ; 32,52)$ & 126,38 \\
\hline 6 & $\mathrm{f}(34,77 ; 31,91)$ & 117,92 & 16 & $\mathrm{f}(29,91 ; 31,05)$ & 110,48 \\
\hline 7 & $\mathrm{f}(30,83 ; 32,23)$ & 109,87 & 17 & $\mathrm{f}(69,01 ; 31,12)$ & 141,43 \\
\hline 8 & $\mathrm{f}(33,42 ; 31,73)$ & 125,91 & 18 & $\mathrm{f}(29,2 ; 32,46)$ & 131,15 \\
\hline 9 & $\mathrm{f}(43,3 ; 30,16)$ & 129,69 & 19 & $\mathrm{f}(39,2 ; 30,5)$ & 138,26 \\
\hline 10 & $\mathrm{f}(51,82 ; 31,35)$ & 138,39 & 20 & $\mathrm{f}(45,76 ; 30,48)$ & 106,47 \\
\hline
\end{tabular}


прогнозування ТП збагачення магнетитових кварцитів (на прикладі показників переділу 1-ї стадії секції РЗФ Південного ГЗК). Тоді завдання оптимізації у спрощеній формі зводиться до знаходження максимуму функції:

$$
f\left(\chi_{1}, \chi_{2}\right)=Q\left(\beta, \beta_{x}\right) \rightarrow \max ,
$$

де $Q$ - продуктивність секції збагачення, т/год.; $\beta$ - вміст фракції 10-20 мм, \%; $\mathrm{Fe}_{3}$ - вміст корисного компоненту (заліза загального), \%.

Крім того, приймемо інтервали зміни аргументів функції мети 28,6 $<\beta<71,02$ та $30<\mathrm{Fe}_{3}<32,56$, розмір популяції $M=20$, ймовірності схрещування $p_{c}=0,25$, ймовірності мутації $p_{m}=0,25$.

Припустимо, що необхідна точність становить 2 цифри після коми для кожної змінної. Тоді діапазон для змінної $x_{1}$, що становить $42,42 \%$, має бути розділений на 42,42 х 100 рівних відрізків. Це означає, що для першої частини хромосоми буде потрібно 13 бітів, тому що $2^{12}<4242<2^{13}$.

Для другої змінної $\chi_{2} 3$ діапазоном, що дорівнює 2,56\%, умова встановленої точності вимагає, щоб весь діапазон був розділений на 2,56 х 100 рівних відрізків. Таким чином, для цієї змінної необхідно 12 бітів, оскільки $2^{11<2560<2^{12}}$.

Загальна довжина хромосоми (вектор потенційного рішення) становитиме $m=13+12=$ 25 бітів, з яких перші 13 кодують першу змінну, а ті 12, що лишилися, - другу змінну.

Створимо початкову популяцію, що складається 320 рядків, у кожній з яких значення 25 бітів будуть ініційовані випадковим способом (табл. 1).

Тепер необхідно декодувати кожну хромосому й обчислити функцію придатності кожного рядка (визначається шляхом обчислення відповідних значень функції, що оптимізується). Після декодування одержуємо результат, показаний у табл. 2.

3 отриманих даних видно, що друга хромосома має найменшу придатність, а хромосома $a_{15}$ - найбільшу.

Перейдемо до конструювання рулетки, необхідної для процесу селекції. Загальна придатність всієї популяції становить величину

$$
F=\sum_{j=1}^{20} \mu\left(a_{j}\right)=2538,95 .
$$

Імовірності вибору $p_{j}$ для кожної хромосоми, відповідно до вищевказаного правила, наведені в табл. 3.

Кумулятивні ймовірності для кожної хромосоми наведені в табл. 4.
Далі необхідно зробити 20 обертів рулетки, щораз відбираючи єдину хромосому для нової популяції. Нехай випадкова послідовність 20 чисел із діапазону $[0,1]$ має вигляд, показаний у табл. 5.

Перше число $r_{1}$, більше, ніж $q_{10}$ і менше, ніж $q_{11}$, тому для нової популяції вибирається хромосома $a_{11}$; друге число $r_{2}$ більше, ніж $q_{3}$ і менше, ніж $q_{4}$, отже, другим для нової популяції вибирається рядок $a_{4}$ і т.д.

Остаточно нова популяція має вигляд, наведений у табл. 6.

Таблиця 3

Значення ймовірностей кожної хромосоми

\begin{tabular}{|c|c|c|c|}
\hline Рядок & Імовірність $\boldsymbol{p}_{j}$ & Рядок & Імовірність $\boldsymbol{p}_{j}$ \\
\hline 1 & 0,0511 & 11 & 0,0539 \\
\hline 2 & 0,0432 & 12 & 0,0507 \\
\hline 3 & 0,0477 & 13 & 0,0495 \\
\hline 4 & 0,0550 & 14 & 0,0531 \\
\hline 5 & 0,0539 & 15 & 0,0498 \\
\hline 6 & 0,0464 & 16 & 0,0435 \\
\hline 7 & 0,0433 & 17 & 0,0557 \\
\hline 8 & 0,0496 & 18 & 0,0517 \\
\hline 9 & 0,0511 & 19 & 0,0545 \\
\hline 10 & 0,0545 & 20 & 0,0419 \\
\hline
\end{tabular}

Як видно з табл. 6, гірша в початковій популяції (рядок 2) після селекції не потрапила в наступну генерацію, а краща в початковій популяції (рядок 15) з'явилася в новій популяції три рази.

Таблиця 4

Кумулятивні ймовірності кожної хромосоми

\begin{tabular}{|c|c|c|c|}
\hline Рядок & Імовірність $\boldsymbol{q}_{\boldsymbol{i}}$ & Рядок & Імовірність $\boldsymbol{q}_{\boldsymbol{i}}$ \\
\hline 1 & 0,067 & 11 & 0,538 \\
\hline 2 & 0,086 & 12 & 0,577 \\
\hline 3 & 0,137 & 13 & 0,647 \\
\hline 4 & 0,181 & 14 & 0,698 \\
\hline 5 & 0,247 & 15 & 0,776 \\
\hline 6 & 0,293 & 16 & 0,837 \\
\hline 7 & 0,335 & 17 & 0,873 \\
\hline 8 & 0,381 & 18 & 0,912 \\
\hline 9 & 0,423 & 19 & 0,964 \\
\hline 10 & 0,478 & 20 & 1,000 \\
\hline
\end{tabular}

Таблиця 5

Випадкові числа 3 діапазону [0, 1]

\begin{tabular}{|l|l|l|l|l|}
\hline 0,513 & 0,175 & 0,308 & 0,534 & 0,947 \\
\hline 0,171 & 0,702 & 0,226 & 0,494 & 0,424 \\
\hline 0,703 & 0,389 & 0,227 & 0,368 & 0,983 \\
\hline 0,005 & 0,765 & 0,646 & 0,767 & 0,780 \\
\hline
\end{tabular}


Інформатика, обчислювальна техніка та автоматизація

Таблиця 8

Популяція хромосом після схрещування

\begin{tabular}{|c|c|c|c|}
\hline № & Xромосома & № & Хромосома \\
\hline 1 & 1110110101100001101111000 & $11^{*}$ & 1001010011010111111000101 \\
\hline $2^{*}$ & 0101101011010111111000101 & 12 & 1010001000110000001000110 \\
\hline 3 & 1101110000100011111011110 & $13^{*}$ & 1110110101100000000111011 \\
\hline 4 & 0000001111111010011011111 & 14 & 1110110101100001101111000 \\
\hline 5 & 0101101001111000001110010 & 15 & 0001110100010110101100111 \\
\hline 6 & 1101110000100011111011110 & 16 & 1101110000100011111011110 \\
\hline 7 & 1110110101100001101111000 & 17 & 0011111111110000110001100 \\
\hline 8 & 1101110000100011111011110 & $18^{*}$ & 1000110000011011101111000 \\
\hline 9 & 000011010111011011111011 & 19 & 0110011110011000101111110 \\
\hline 10 & 1001010011010111111000101 & 20 & 0000001110100111110101101 \\
\hline
\end{tabular}

Примітка: * - схрещені хромосоми

Таблиця 6 цьому разі число відібраних хромосом вийшло

Нова популяція хромосом ГА

\begin{tabular}{|c|c|c|}
\hline $\begin{array}{c}\text { Новий } \\
\text { номер } \\
\text { рядка }\end{array}$ & Хромосома & $\begin{array}{c}\text { Старий } \\
\text { номер } \\
\text { рядка }\end{array}$ \\
\hline 1 & 1110110101100001101111000 & 11 \\
\hline 2 & 0101101001111000001110010 & 4 \\
\hline 3 & 1101110000100011111011110 & 15 \\
\hline 4 & 0000001111111010011011111 & 1 \\
\hline 5 & 0101101001111000001110010 & 4 \\
\hline 6 & 1101110000100011111011110 & 15 \\
\hline 7 & 1110110101100001101111000 & 11 \\
\hline 8 & 1101110000100011111011110 & 15 \\
\hline 9 & 0000110101111011011111011 & 7 \\
\hline 10 & 1001010011010111111000101 & 5 \\
\hline 11 & 1001010011010111111000101 & 5 \\
\hline 12 & 1010001000110000001000110 & 13 \\
\hline 13 & 1110110101100001101111000 & 11 \\
\hline 14 & 1110110101100001101111000 & 11 \\
\hline 15 & 0001110100010110101100111 & 8 \\
\hline 16 & 1101110000100011111011110 & 15 \\
\hline 17 & 0011111111110000110001100 & 19 \\
\hline 18 & 1000110000011010000111011 & 10 \\
\hline 19 & 0110011110011000101111110 & 20 \\
\hline 20 & 0000001110100111110101101 & 18 \\
\hline & & \\
\hline
\end{tabular}

Наступним кроком у проведенні ГА є схрещування. Застосуємо його до отриманої нової популяції. Задана ймовірність схрещування становить величину $p_{c}=0,25$, тому в середньому має піддатися схрещуванню $25 \%$ вихідних хромосом. Тут робимо в такий спосіб: для кожної хромосоми в новій популяції генеруємо випадкове число $r$ з діапазону $[0,1]$; якщо $r<0,25$, то вибираємо цю хромосому для схрещування.

3 табл. 7 помітно, що для схрещування відбираються хромосоми 3 номерами 2, 11, 13 i 18 , оскільки значення випадкових чисел на цих позиціях менше, ніж 0,25. Зазначимо, що в парним, тому легко скласти батьківські пари. У протилежному випадку необхідно додати або забрати одну хромосому. Склад батьківських пар також випадковий, наприклад, однією такою парою виберемо рядки $a_{2}, a_{11}$ й іншою - рядки $a_{13}, a_{18}$. Для кожної із цих двох пар генеруємо випадкове число $s$ діапазону $[1,24]$ (нагадаємо, що 25 - загальне число бітів у хромосомі), що визначає положення точки схрещування. Для першої пари це число становитиме 9, а для другої - 16.

Перша пара хромосом

$a_{2}=01011010 \mid 01111000001110010$; $a_{11}=10010100 \mid 11010111111000101$,

після схрещування дає таку пару нащадків:

$a_{2}{ }^{*}=01011010 \mid 11010111111000101 ; a_{11}{ }^{*}=100101$ $00 \mid 01111000001110010$.

Друга пара хромосом

$a_{13}=111011010110000 \mid 1101111000$; $a_{18}=100011000001101 \mid 0000111011$,

у результаті схрещування дає таку пару нащадків:

$a_{13}{ }^{*}=111011010110000 \mid 0000111011 ; a_{18}{ }^{*}=10001$ $1000001101 \mid 1101111000$.

Таблиця 7

Випадкові числа 3 діапазону $[0,1]$ для процедури схрещування

\begin{tabular}{|l|l|l|l|l|}
\hline 0,82 & 0,15 & 0,62 & 0,31 & 0,34 \\
\hline 0,91 & 0,51 & 0,40 & 0,60 & 0,78 \\
\hline 0,03 & 0,86 & 0,16 & 0,67 & 0,75 \\
\hline 0,58 & 0,38 & 0,20 & 0,35 & 0,82 \\
\hline
\end{tabular}

Після схрещування популяція приймає вигляд, наведений у табл. 8.

Розглянемо роботу оператора мутації, що виконується на побітовій основі. Задана 
ймовірність мутації $p_{m}=0,01$, тому очікуване число бітів, які підлягають мутації, становитиме $1 \%$ від загального числа бітів у популяції. В останній є 33 х 20=660 бітів, отже, у середньому число бітів-мутантів становитиме 6-7 од. Кожен біт у популяції має рівний шанс піддатися мутації, тому для кожного біта генеруємо випадкове число $r$ д діапазону [0,1]; якщо $r<0,01$, то цей біт мутує. Загалом необхідно розіграти 660 випадкових чисел, з яких у цьому разі тільки 5 задовольняють необхідній умові. Положення біта й відповідне значення випадкового числа наведені в табл. 9.

Таблиця 9

Позиція біту, що мутус в популяції

\begin{tabular}{|c|c|}
\hline Позиція біту & Випадкове число \\
\hline 112 & 0,00021 \\
\hline 349 & 0,00994 \\
\hline 418 & 0,00880 \\
\hline 429 & 0,00542 \\
\hline 472 & 0,00283 \\
\hline
\end{tabular}

Для визначення положення біта, що мутував у рядках популяції, скористаємося табл. 10. Помітно, що 5 хромосом піддалися мутації.

Остаточна популяція після операторів схрещування та мутації наведена в табл. 11.
Таблиця 10

Положення біту, що мутував у популяції

\begin{tabular}{|c|c|c|}
\hline $\begin{array}{c}\text { Положення } \\
\text { біту }\end{array}$ & $\begin{array}{c}\text { Номер } \\
\text { хромосоми }\end{array}$ & $\begin{array}{c}\text { Номер біту } \\
\text { у хромосомі }\end{array}$ \\
\hline 112 & 5 & 12 \\
\hline 349 & 14 & 24 \\
\hline 418 & 17 & 18 \\
\hline 429 & 18 & 4 \\
\hline 472 & 19 & 22 \\
\hline
\end{tabular}

У цій же таблиці в останньому стовпчику наведені значення функції придатності, отримані для вихідної популяції після селекції, схрещування й мутації. Кращий рядок має значення функції придатності в останній популяції $Q_{18}=139,91$ т/год., що перевищує найбільшу величину у початковій популяції $\left(Q_{15}=139,56\right.$ т/год.). При цьому збільшується вміст класу 10-20 мм $(54,47 \%)$, та вміст заліза (30,48\%). Крім того, і загальна придатність дорівнює $\mathrm{F}=2583,98$, що перевищує аналогічну величину на початку роботи ГА.

Висновки. Таким чином, за один крок процедури виконання ГА вдалося просунутися вперед на шляху пошуку максимального значення розглянутої функції. Далі необхідно знову застосувати селекцію, схрещування й мутацію, оцінити отриману генерацію $з$ погляду їі придатності тощо доти, поки не буде задовольнятися умова зупинки (рис. 1).

Таблиця 11

Популяція після схрещування та мутації

\begin{tabular}{|c|c|c|}
\hline № & Хромосома & Функція придатності \\
\hline 1 & 1110110101100001101111000 & $\mathrm{f}(67,94 ; 31,11)=136,91$ \\
\hline $2^{*}$ & 0101101011010111111000101 & $\mathrm{f}(43,65 ; 32,49)=129,19$ \\
\hline 3 & 1101110000100011111011110 & $\mathrm{f}(65,09 ; 32,52)=126,38$ \\
\hline 4 & 0000001111111010011011111 & $\mathrm{f}(29,25 ; 31,56)=129,64$ \\
\hline $5^{* *}$ & $010110100111 \mathbf{0} 000001110010$ & $\mathrm{f}(43,59 ; 30,14)=139,56$ \\
\hline 6 & 1101110000100011111011110 & $\mathrm{f}(65,09 ; 32,52)=126,38$ \\
\hline 7 & 1110110101100001101111000 & $\mathrm{f}(67,94 ; 31,11)=136,91$ \\
\hline 8 & 110111000010001111011110 & $\mathrm{f}(65,09 ; 32,52)=126,38$ \\
\hline 9 & 0000110101111011011111011 & $\mathrm{f}(30,83 ; 32,23)=109,87$ \\
\hline 10 & 1001010011010111111000101 & $\mathrm{f}(53,27 ; 32,49)=136,75$ \\
\hline $11^{*}$ & 1001010011010111111000101 & $\mathrm{f}(53,27 ; 32,49)=110,54$ \\
\hline 12 & 1010001000110000001000110 & $\mathrm{f}(55,48 ; 30,09)=128,75$ \\
\hline $13^{*}$ & 1110110101100000000111011 & $\mathrm{f}(67,94 ; 30,07)=116,26$ \\
\hline $14^{* *}$ & 1110110101100001101111010 & $\mathrm{f}(67,94 ; 31,11)=136,91$ \\
\hline 15 & 0001110100010110101100111 & $\mathrm{f}(33,42 ; 31,73)=125,91$ \\
\hline 16 & 1101110000100011111011110 & $\mathrm{f}(65,09 ; 32,52)=126,38$ \\
\hline $17^{* *}$ & $0011111111100001 \underline{0} 0001100$ & $\mathrm{f}(39,2 ; 30,34)=134,19$ \\
\hline $18^{* * *}$ & $100 \underline{1} 110000011011101111000$ & $\mathrm{f}(54,47 ; 32,39)=139,81$ \\
\hline $19^{* *}$ & 0110011110011000101111110 & $\mathrm{f}(45,76 ; 30,48)=136,11$ \\
\hline 20 & $00000011101001111010 \underline{\mathbf{0}} 101$ & $\mathrm{f}(29,2 ; 32,45)=131,15$ \\
\hline
\end{tabular}

Примітки: * - схрещені хромосоми; ** - рядки, піддані мутаиії; $\underline{\mathbf{0}}, \underline{\mathbf{1}}$ - біти, значення яких було змінено у процесі мутації 


\section{Список літератури:}

1. Купін А.І., Сенько А.О., Мисько Б.С. Ідентифікація та автоматизоване керування в умовах процесів збагачувальної технології на основі методів обчислювального інтелекту : монографія / ред. О.Г. Самойлюк. Кривий Ріг, 2018. 298 с.

2. Zhang B., H. Muhlenbein Evolving optimal neural networks using genetic algorithms with Occam's rasor. Complex systems. 1993. № 7. P. 199-220.

3. Goldberg D.E. Genetic Algorithms in Search, Optimization, and Machine Learning. Mass. : Addison-Wesly, 1989. $412 \mathrm{p}$.

4. Купін А.І. Інтелектуальна ідентифікація та керування в умовах процесів збагачувальної технології : монографія. Кривий Ріг : КТУ, 2008. 204 с.

5. Купін А.І. Еволюційна оптимізація параметрів технологічного процесу збагачення магнетитових кварцитів. Вісник Житомирського державного технологічного університету. Житомир, 2008. № 4. С. $230-239$.

6. Денисов А.А., Колесников Д.Н. Теория больших систем управления. Ленинград : Энергоиздат. Ленингр. отд-ние, 1982. 287 с.

7. Молчанов А.А. Моделирование и проектирование сложных систем. Киев : Вища школа, 1988. 359 с.

\section{Kupin A.I., Senko A.O., Mysko B.S. OPTIMIZATION BASED}

\section{ON A GENETIC APPROACH TO THE PROCESS OF IRON ORE BENEFICIATION}

Given that the task of optimizing the process of iron ore enrichment is a task of global optimization in the conditions of non-stationarity and nonlinearity, the principles of genetic algorithms were applied to solve it. In the course of the study, the optimization of the multidimensional objective function was formed, which was formed in the process of neural network identification of the technological process of enrichment of magnetite quartzites. It is considered that all possible restrictions in the form of equalities or inequalities have already been taken into account in the objective function in the form of a convolution of criteria, by the method of penalty functions or otherwise. For simplicity, we assume that the purpose function will include only performance, size class, iron content. Although a similar technique can be applied to more factors. Nevertheless, regardless of the choice of the main criterion, it is known that the minimization and maximization problems are equivalent. In each generation, each chromosome is evaluated for its suitability using the function $f$ on the decoded set of variables. A new population is selected based on calculated fitness. With the help of crossing and mutation operators, chromosomes are combined into a new population. After selection, crossing and mutation, the new population is ready for further evaluation. The estimates obtained are used to construct a new roulette with sectors proportional to the current value of the fitness function. The other part of evolution is a cyclic repetition of the process. After a number of generations, when there is no population improvement, the best chromosome is the optimal solution. A forced stop of the algorithm after a fixed number of iterations is also possible. Genetic operators of selection and mutation have been applied. This made it possible to move forward in the search for the maximum value of the function under consideration.

Key words: genetic algorithms, optimization, iron ore dressing, intersection, mutation. 